\title{
Roland Barthes, "Sarrasine" de Balzac. Séminaires à l'École pratique des hautes études (1967-1968 et 1968-1969)
}

\section{Rachele Calisti}

\section{(2) OpenEdition \\ Journals}

Edizione digitale

URL: http://journals.openedition.org/studifrancesi/3854

DOI: 10.4000/studifrancesi.3854

ISSN: 2421-5856

\section{Editore}

Rosenberg \& Sellier

\section{Edizione cartacea}

Data di pubblicazione: 1 décembre 2012

Paginazione: 609

ISSN: 0039-2944

\section{Notizia bibliografica digitale}

Rachele Calisti, «Roland Barthes, "Sarrasine" de Balzac. Séminaires à l'École pratique des hautes études (1967-1968 et 1968-1969)», Studi Francesi [Online], 168 (LVI | III) | 2012, online dal 30 novembre 2015, consultato il 07 mars 2021. URL: http://journals.openedition.org/studifrancesi/3854 ; DOI: https:// doi.org/10.4000/studifrancesi.3854

Questo documento è stato generato automaticamente il 7 mars 2021.

\section{cc) $($ ) $\ominus$}

Studi Francesi è distribuita con Licenza Creative Commons Attribuzione - Non commerciale - Non opere derivate 4.0 Internazionale. 


\title{
Roland Barthes, "Sarrasine" de Balzac. Séminaires à l'École pratique des hautes études (1967-1968 et 1968-1969)
}

\author{
Rachele Calisti
}

\section{NOTIZIA}

ROLAND BARTHES, “Sarrasine" de Balzac. Séminaires à l'École pratique des hautes études

(1967-1968 et 1968-1969), Paris, Seuil, 2011, pp. 597.

1 Nel 1960 Roland Barthes realizza finalmente la sua carriera di studioso: rimasto troppo a lungo ai margini del mondo accademico ufficiale, entra nella prestigiosa École pratiques des hautes études en Sciences économiques et sociales. Qui terrà i suoi seminari fino al 1976: le lezioni in poco tempo diverranno tra le più seguite e note di Parigi, con studenti ammassati fin sulle scale per ascoltare le sue affascinanti sintesi. Proprio grazie al lavoro svolto durante i seminari tra il 1967 e il 1969, nel 1970 pubblica S/Z: non semplicemente una critica alla novella balzacchiana Sarrasine, ma piuttosto una sua riscrittura. Un libro, dunque, ancora assolutamente anti-universitario in cui Barthes si allontana dai suoi primi interessi come la semiologia e lo strutturalismo per dirigere la riflessione verso un'idea più dinamica della letteratura, rivolgendo un'attenzione sempre maggiore alla polisemia del testo, alla pluralità del senso. I seminari, momento di concreta messa in pratica di un metodo di analisi, rappresentano allora un punto di rottura rispetto al passato e inaugurano una concezione moderna della critica in cui la "lettura" coincide con la letteratura stessa. Barthes si riavvicina progressivamente al lettore, unico soggetto in grado di dare vita a un libro, altrimenti destinato a rimanere un oggetto inerte. E come ogni lettura di Sarrasine riflette la possibilità di dare vita a un testo plurale attraverso un nuovo significato che ogni lettore può rintracciare all'interno di questo "tessuto", allo stesso modo il seminario rappresenta un tipo di condivisione del sapere che non appartiene solo a un uomo, ma si dissemina liberamente tra molti, mosso dal desiderio di condivisione, realizzando 
così un diverso modo di fare critica e, contemporaneamente, di leggere un'opera. Il lavoro letterario nasce così all'interno di una sorta di circolarità: può essere costantemente reinterpretato, riscritto, ricominciando ogni volta il circolo dell'interpretazione.

2 Sarrasine de Balzac. Séminaires à l'École pratique des hautes études non è perciò un'opera vera e propria ma la ricostruzione del seminario, una «traversée des notes prises par Barthes en vue de son cours» (p.19). La struttura del testo ripercorre le séances tenute da Barthes influenzate, a differenza di $S / Z$, dalla necessità di illustrare oralmente l'analisi di un testo a un pubblico di studenti e dall'effervescente clima di rivolta di quegli anni (testimoniato, in particolare, dalla lezione alla rentrée accademica del 21 novembre 1968 nel corso della quale Barthes si allontana per qualche ora dalla novella di Balzac per condannare la nuova riforma universitaria del ministro Edgar Faure). Il lavoro permette così di fissare, con i necessari accorgimenti, pubblicandole, delle note concepite essenzialmente per essere rielaborate in un contesto orale e destinate soprattutto ad un uso personale come aide-mémoire. Tuttavia, l'attento impegno di chiarificazione dei curatori del testo, Claude Coste e Andy Stafford guidati da Éric Marty, ha reso possibile ricreare un'opera dotata di una propria autonomia e coerenza, che consente non solo «de faciliter la liberté du lecteur dans le pluriel du texte» (p. 50) ma soprattutto permette alla voce di Barthes di arrivare fino al presente, mantenendo viva la riflessione del critico mostrandola nell'atto stesso di compiersi, come un work in progress (p.19) in attesa di trovare finalmente espressione nell'espace littéraire, attraverso l'attività concreta della scrittura. 